Original Article

\title{
DEVELOPMENT AND VALIDATION OF A SIMPLE HPLC METHOD FOR ESTIMATION OF MYCOPHENOLATE MOFETIL IN MICROEMULSION FORMULATION
}

\author{
PALAKDEEP KAUR, MOHIT KUMAR, UTTAM KUMAR MANDAL ${ }^{*}$
}

Department of Pharmaceutical Sciences and Technology, Maharaja Ranjit Singh Punjab Technical University (MRSPTU), Badal Road, Bathinda, Punjab 151001, India

Email: mandalju2007@gmail.com

Received: 02 Jan 2020, Revised and Accepted: 17 Feb 2020

\section{ABSTRACT}

Objective: The present study deals with the development, validation and application of a simple, precise and accurate HPLC method for the determination of mycophenolate mofetil in pharmaceutical formulations and microemulsions.

Methods: In this method, a simple isocratic mobile phase composition of methanol and water (75:25 v/v) pumped at $1 \mathrm{ml} / \mathrm{minute}$ flow rate through Phenomenex C18 column (dimension: $250 \times 4.6 \mathrm{~mm}$ and $5 \mu \mathrm{m}$ particle size) was used. Injection volume was $20 \mu \mathrm{l}$ and analysis of mycophenolate mofetil was carried out at $250 \mathrm{~nm}$.

Results: The coefficient of regression was found to be 0.9996 , indicating the linearity of the developed method within a range of 0.1 to $10 \mu \mathrm{g} / \mathrm{ml}$. The limit of detection (LOD) and the limit of quantization (LOQ) were found to be $3.660 \mathrm{ng} / \mathrm{ml}$ and $11.091 \mathrm{ng} / \mathrm{ml}$, respectively. The results showed that \% deviation for change in compositions of the mobile phase, flow rate and temperature was within a range of-5.51 to $10.99 \%,-3.70$ to $8.80 \%$ and-5.29 to $10.90 \%$, respectively. The method seemed sensitive to change of temperature $\left( \pm 5{ }^{\circ} \mathrm{C}\right)$ and methanol composition $( \pm 2 \%)$ as the results were at the boundary limit of $10 \%$ deviation.

Conclusion: A simple, precise and accurate HPLC method for the determination of drug content from microemulsion has been developed and validated in accordance with ICH guidelines.

Keywords: Mycophenolate Mofetil, High-performance liquid chromatography (HPLC), Validation, Psoriasis, Microemulsion

(C) 2020 The Authors. Published by Innovare Academic Sciences Pvt Ltd. This is an open access article under the CC BY license (http://creativecommons.org/licenses/by/4.0/) DOI: http://dx.doi.org/10.22159/ijpps.2020v12i4.36750. Journal homepage: https://innovareacademics.in/journals/index.php/ijpps

\section{INTRODUCTION}

Mycophenolate Mofetil (MMF) is 2-(morpholin-4-yl) ethyl (4E)-6(4hydroxy-6-methoxy-7-methyl-3-oxo l, 3 dihydroisobenzofuran-5yl)-4-methylhex-4-enoate (fig. 1). It belongs to BCS Class II of drugs characterized by a strongly $\mathrm{pH}$-dependent solubility profile [1]. It is an immune-suppressant and prodrug of Mycophenolic Acid (MPA), extensively used to prevent rejection in organ transplantation [2]. MPA, a product of a Penicillium fungus, was originally isolated in 1896. The immunological activity of the drug is accomplished through rapid hydrolysis (in vivo) of the morpholino-ethyl ester, MMF, to the active acid form, MPA [3, 4]. It is a reversible inhibitor of inosine monophosphate dehydrogenase (IMPDH) in purine biosynthesis, which is necessary for the growth of T cells and B cells. MPA has antineoplastic, anti-viral, anti-fungal and immunosuppressive activity [5]. MMF has recently been added to therapeutic regimens for skin disorders and it is being actively researched for the treatment of psoriasis [6, 7]. There are few reports of dermal formulations in the form of the microemulsion, where MMF should be estimated accurately during the formulation development stage. Instead of UV method, a validated HPLC method for the estimation of MMF is very much essential as it gives accurate and precise results.<smiles>COc1c(C)c2c(c(O)c1C/C=C(\C)CCC(=O)OCCN1CCOCC1)C(=O)OC2</smiles>

Fig. 1: Structure of mycophenolate mofetil
According to the guideline Q2 (R1) of ICH, "quantitative tests of the active moiety in samples of the drug substance or drug product or other selected component(s) in the drug product" is one of the types of analytical procedures to be validated [8]. The validation of an analytical procedure ensures that the applied analytical technique, such as HPLC, shall give reliable and reproducible results. This process is very important because it provides information about the linearity, accuracy, precision, robustness and sensitivity of the method, proving its suitability to the intended application.

There are few published HPLC methods for the estimation of MMF in bulk and plasma samples. Reddy et al. [9] and Rao et al. [10] reported such methods for the determination of MMF in tablet dosage forms in which mobile phase consisted of acetonitrile and phosphate buffer. Tsina et al. [11] reported manual and automated HPLC methods for the determination of MMF in human plasma in which mobile phase consisted of $0.05 \mathrm{M}$ acetonitrile, citratephosphate buffer ( $\mathrm{pH} 3.6)$ and $0.02 \mathrm{M}$ heptane sulfonic acid. All these published methods have some significant shortcomings. Their mobile phases have buffers as aqueous composition as compared to only pure water used for our method. Buffer system creates problems as it chokes the analytical column if it is not washed thoroughly after the analysis is over. This buffer system is highly susceptible to bacterial growth when it is stored. As compared to that, our developed HPLC method has a simple mobile phase composition of water and methanol only. Moreover, the sensitivity of the developed method is quite high as compared to earlier published methods. Also, there is no reported HPLC method, which was solely developed for the estimation of MMF in micro emulsion formulation.

So, the objective of the present study was to develop and validate a simple HPLC method useful for the estimation of MMF in microemulsion formulation. Various analytical parameters such as linearity, precision, accuracy, robustness, the limit of detection 
(LOD) and limit of quantification (LOQ) were evaluated as per ICH Q2 (R1) guidelines [8].

\section{MATERIALS AND METHODS}

\section{Instrumentation}

The separation was carried out on an isocratic HPLC system (Waters 1525 UV system) attached with binary HPLC pump, Waters 2489 UV-Visible detector, Empower 3 software and RP-C18 column (250 $\mathrm{mm} \times 4.6 \mathrm{~mm}$; particle size $5 \mu \mathrm{m}$ ).

\section{Drugs and chemicals}

Mycophenolate Mofetil pure drug was obtained as a gift sample from Conchord Biotech, Ahmedabad, India. Labrasol, was obtained as gift samples from Gattefosse India Private Limited, Mumbai. Oleic Acid and arlasolve were donated by Croda, USA. Methanol of HPLC grade, methylparaben and propylparaben were purchased from Loba Chemie Pvt. Ltd., India. Ultrapure type I water was obtained from Millipure Direct Q, Merck installed at our Department.

\section{Chromatographic conditions}

The mobile phase consisting of methanol (HPLC grade) and ultrapure type I water was sonicated and degassed using a bath sonicator before use. It was pumped from the solvent reservoir in the ratio of $75: 25 \mathrm{v} / \mathrm{v}$ (methanol: water) into the C18 column at a flow rate of $1 \mathrm{ml} / \mathrm{min}$. The column was allowed to equilibrate for 0.5 $\mathrm{h}$ with the mobile before starting the sample run. $20 \mu \mathrm{l}$ sample was injected and the elution was monitored at $250 \mathrm{~nm}$ for a time of 10 $\mathrm{min}$. The whole analysis was performed at $30^{\circ} \mathrm{C}$.

\section{Preparation of standard curve (Linearity)}

Standard stock solution of MMF was prepared by dissolving $50 \mathrm{mg}$ pure drug in $50 \mathrm{ml}$ standard volumetric flask with methanol followed by sonication for $5 \mathrm{~min}$. The obtained solution of $1 \mathrm{mg} / \mathrm{ml}$ was further diluted to prepare six standard concentrations namely $0.1,0.2,0.5,2.5,5$ and $10 \mu \mathrm{g} / \mathrm{ml}$. Each standard concentration was run in triplicates and the average value was used for the preparation of standard curve by plotting concentration vs peak area. Standard curve was constructed with peak area (Y-axis) against concentration (X-axis) followed by estimation of coefficient of correlation using Microsoft excel. The amount of MMF present in the sample was calculated through the standard curve.

\section{Sensitivity}

Sensitivity of the developed method was determined through estimation of limit of detection (LOD) and limit of quantification (LOQ). Limit of detection (LOD) is the lowest amount of analyte in the sample that can be detected, but not necessarily quantitated as an exact value, under the stated conditions of the test. It gives a signal-to-noise ratio of about 3:1. Limit of quantification (LOQ) is the lowest amount of analyte in the sample that can be quantitatively determined with acceptable precision and accuracy under the stated conditions of the test. It gives a signal-to-noise ratio of about 10:1. The LOD and LOQ of the proposed method were determined from the standard curve prepared from standards concentrations in the lower ranges $(100,200,300,400,500$ and $600 \mathrm{ng} / \mathrm{ml})$ by using following equations [12]:

$$
\begin{aligned}
& \mathrm{LOD}=3.3^{\frac{\sigma}{5}} \times 100 \\
& \mathrm{LOQ}=10^{\frac{\sigma}{5}} \times 100 \text {------Equation1 }
\end{aligned}
$$

Where,

$\sigma$ is standard deviation of intercepts of calibration curve equations.

$\mathrm{S}$ is the mean of slopes of the related calibration curve equations.

\section{Accuracy and precision}

Accuracy and precision were estimated at three different levels corresponding to $80 \%, 100 \%$ and $120 \%$ of target concentration i.e. $3.2,4.0$ and $4.8 \mu \mathrm{g} / \mathrm{ml}$. six replicates of each sample were prepared and analyzed. Precision is expressed as \% coefficient of variation $(\% \mathrm{CV})$, while accuracy is measured as $\%$ nominal as per the following equations [13].

$$
\begin{aligned}
& \text { Accuracy (\% nominal) }=\frac{\text { Obtainea Cone }}{\text { True Conf }} \times \text { 100-----Equation3 } \\
& \text { Precision }(\mathrm{CV} \%)=\frac{S_{0} \cdot D_{m}}{\operatorname{Mean}} \times 100 \text {-----Equation4 }
\end{aligned}
$$

Where, SD is standard deviation.

\section{Robustness}

Robustness of the proposed method was determined by making slight deliberate changes in the experimental procedures. In this method, the following changes were applied:

- Temperature: $\pm 5^{\circ} \mathrm{C}$

- Flow rate: $\pm_{0.1 \mathrm{ml} / \mathrm{min}}$

- Concentration of methanol in the mobile phase: $\pm_{2 \%}$

Concentration of $4 \mu \mathrm{g} / \mathrm{ml}$ was run with the above conditions and a change of $<10 \%$ in its assay was considered the developed method as robust.

\section{Stability studies}

These include testing of samples that may result in some changes during storage and are likely to influence the obtained results. A stability study of the proposed method was checked by analyzing the sample at $100 \%$ of the target concentration $(4 \mu \mathrm{g} / \mathrm{ml})$ by storing the sample for $24 \mathrm{~h}$ followed by measuring its peak areas after appropriate dilution with methanol. The study was repeated in triplicate $(\mathrm{n}=3)$.

\section{Application of the developed HPLC Method}

The developed HPLC method was applied to determine the content (assay) of MMF from a developed microemulsion formulation. 1\% MMF microemulsion formulation had the composition of oleic acid, labrasol, arlasolve, methylparaben and propylparaben. A volume of $0.2 \mathrm{ml}$ formulation was taken and diluted with methanol to an appropriate concentration. The sample was filtered and analyzed by the developed HPLC method.

\section{RESULTS}

A representative chromatogram of $10 \mu \mathrm{g} / \mathrm{ml}$ MMF sample run at previously mentioned chromatographic conditions is given in fig. 2 . The retention time of MMF was found to be $6.964 \mathrm{~min}$ and accordingly, a run time of $10 \mathrm{~min}$ was fixed for all the analysis.

\section{Linearity and range}

The calibration curve was prepared within a range of $0.1 \mu \mathrm{g} / \mathrm{ml}$ to $10 \mu \mathrm{g} / \mathrm{ml}$ by plotting concentration in X-axis and peak area in Y-axis. The obtained peak areas of individual calibration standards for three replicates are presented in table 1 . Overlay chromatograms of the standard concentrations is provided in fig. 3. The constructed calibration curve over the concentration range of $0.1-10 \mu \mathrm{g} / \mathrm{ml}$ is shown in fig. 4. From the regression analysis, the standard curve equation was found to be $y=40263 x+5350.7$ and the coefficient of correlation value 0.9996 . The LOD and LOQ were found to be 3.66 $\mathrm{ng} / \mathrm{ml}$ and $11.09 \mathrm{ng} / \mathrm{ml}$, respectively, which indicates that the developed method was quite sensitive.

\section{Accuracy and precision}

Accuracy and precision were determined by 3 different levels i.e. 80 , 100 and $120 \%$ of target concentration at $250 \mathrm{~nm}$ using Waters 1489 UV-visible detector. Nominal \% results represent accuracy data, while $\% \mathrm{CV}$ results are used for precision. Accuracy of the developed HPLC method ranged from $90.26 \%$ to $100.82 \%$, whereas precision results were within a range of 0.73 to $2.98 \%$. The results of accuracy and precision for the developed HPLC method are given in table 2 . 


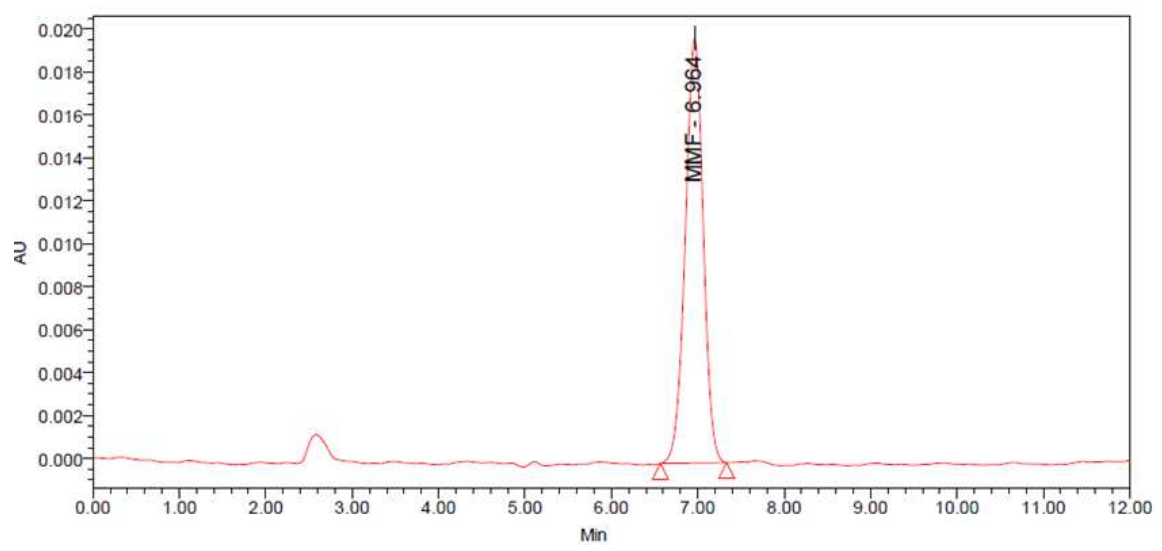

Fig. 2: A typical RP-HPLC chromatogram of mycophenolate mofetil $(10 \mu \mathrm{g} / \mathrm{ml})$ showing retention time $6.964 \mathrm{~min}$

Table 1: Linearity of MMF using RP-HPLC technique

\begin{tabular}{|c|c|c|c|c|}
\hline Concentration $(\mu \mathrm{g} / \mathrm{ml})$ & Area1 $\left(\mu V^{*}\right.$ sec. $)$ & Area2 $\left(\mu V^{*}\right.$ sec. $)$ & Area $3\left(\mu V^{*}\right.$ sec.) & 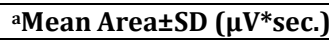 \\
\hline 0.1 & 6915 & 9124 & 8556 & $8198.33 \pm 1147.11$ \\
\hline 0.2 & 13202 & 15779 & 13698 & $14226.33 \pm 1367.33$ \\
\hline 0.5 & 31085 & 30896 & 28507 & $30162.67 \pm 1436.96$ \\
\hline 2.5 & 110397 & 110071 & 99154 & $106540.67 \pm 6399.12$ \\
\hline 5 & 217847 & 211238 & 196094 & $208393.00 \pm 11152.07$ \\
\hline 10 & 385260 & 416054 & 418909 & $406741.00 \pm 18657.78$ \\
\hline
\end{tabular}

amean \pm SD for 3 determinations

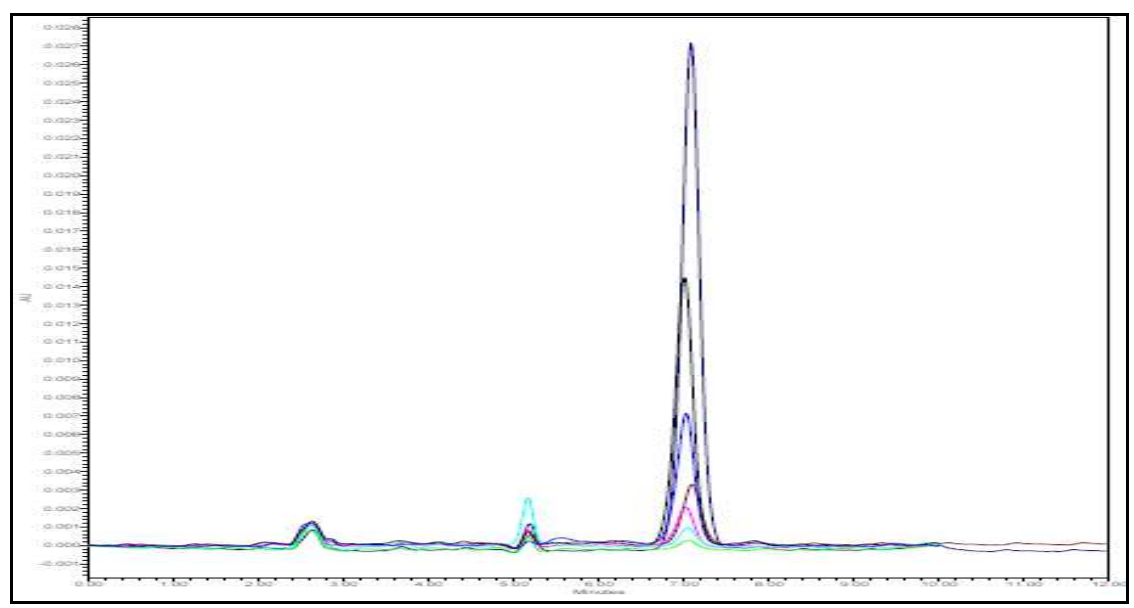

Fig. 3: Overlay chromatogram of the standard concentrations

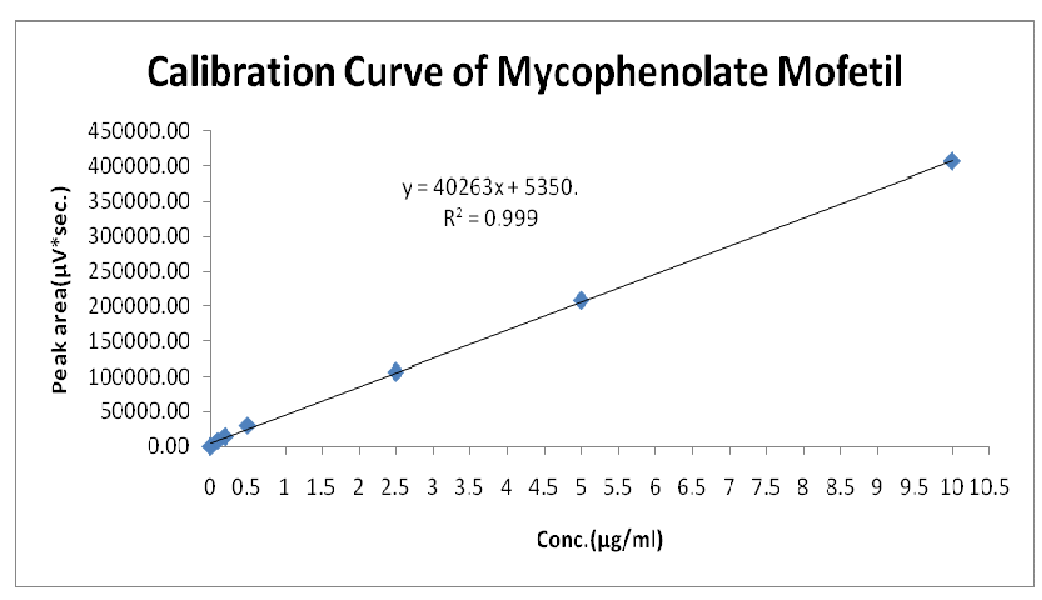

Fig. 4: Standard curve of mycophenolate mofetil at $250 \mathrm{~nm}$ 
Table 2: Results of accuracy and precision for the HPLC method

\begin{tabular}{|c|c|c|c|c|c|c|c|c|c|c|}
\hline \multirow{2}{*}{$\begin{array}{l}\text { True conc. } \\
\text { ( } \boldsymbol{\mu g} / \mathbf{m l})\end{array}$} & \multicolumn{6}{|c|}{ Observed conc. $(\mu \mathrm{g} / \mathrm{ml})$} & \multirow{2}{*}{$\begin{array}{l}\text { aMean conc. } \\
(\boldsymbol{\mu g} / \mathbf{m l}) \\
3.130\end{array}$} & \multirow{2}{*}{$\begin{array}{l}\text { SD } \\
0.030\end{array}$} & \multirow{2}{*}{$\begin{array}{l}\begin{array}{l}\text { Nominal \% } \\
\text { (accuracy) }\end{array} \\
97.81\end{array}$} & \multirow{2}{*}{$\begin{array}{l}\begin{array}{l}\text { CV\% } \\
\text { (Precision) }\end{array} \\
0.95\end{array}$} \\
\hline & 3.165 & 3.166 & 3.129 & 3.115 & 3.109 & 3.095 & & & & \\
\hline 4.0 & 3.755 & 3.687 & 3.672 & 3.501 & 3.531 & 3.516 & 3.610 & 0.107 & 90.26 & 2.98 \\
\hline 4.8 & 4.857 & 4.852 & 4.884 & 4.785 & 4.847 & 4.812 & 4.840 & 0.036 & 100.82 & 0.73 \\
\hline
\end{tabular}

aMean for 6 determinations

\section{Robustness}

Robustness of the developed analytical method was tested by evaluating the influence of minor modifications in HPLC conditions on system suitability parameters of the proposed method. The results of robustness testing are summarized in table 3,4 and 5 .

\section{Stability studies}

MMF sample of $4 \mu \mathrm{g} / \mathrm{ml}$ (correspond to $100 \%$ of target concentration) was stored for $24 \mathrm{~h}$ at room temperature and then analyzed and \% degradation of the sample was determined. The results of the same are provided in table 6.

Table 3: Results of robustness with respect to change in composition of mobile phase

\begin{tabular}{|c|c|c|c|c|c|}
\hline Water: methanol (v/v) & Run $1(\mu \mathrm{g} / \mathrm{ml})$ & Run $2(\mu \mathrm{g} / \mathrm{ml})$ & Run $3(\mu \mathrm{g} / \mathrm{ml})$ & aMean conc. \pm SD $(\mu \mathrm{g} / \mathrm{ml})$ & \% Deviation \\
\hline $24: 76$ & 3.414 & 3.535 & 3.554 & $3.501 \pm 0.076$ & -5.51 \\
\hline $25: 75$ & 3.755 & 3.687 & 3.672 & $3.705 \pm 0.044(100 \%)$ & ---- \\
\hline $26: 74$ & 4.109 & 4.13 & 4.096 & $4.112 \pm 0.017$ & +10.99 \\
\hline
\end{tabular}

amean \pm SD for 3 determinations

Table 4: Results of robustness for change in flow rate

\begin{tabular}{|c|c|c|c|c|c|}
\hline Flow rate $(\mathrm{ml} / \mathrm{min})$ & Run $1(\mu \mathrm{g} / \mathrm{ml})$ & Run $2(\mu \mathrm{g} / \mathrm{ml})$ & Run $3(\mu \mathrm{g} / \mathrm{ml})$ & aMean conc. \pm SD $(\mu \mathrm{g} / \mathrm{ml})$ & \% Deviation \\
\hline 0.9 & 3.825 & 3.859 & 3.842 & $3.842 \pm 0.017$ & -3.70 \\
\hline 1 & 3.755 & 3.687 & 3.672 & $3.705 \pm 0.044(100 \%)$ & --- \\
\hline 1.1 & 3.397 & 3.359 & 3.381 & $3.379 \pm 0.019$ & +8.80 \\
\hline
\end{tabular}

amean \pm SD for 3 determinations

Table 5: Results of robustness for change in temperature

\begin{tabular}{|c|c|c|c|c|c|}
\hline Temperature $\left({ }^{\circ} \mathbf{C}\right)$ & Run $1(\mu \mathrm{g} / \mathrm{ml})$ & Run $2(\mu \mathrm{g} / \mathrm{ml})$ & Run $3(\mu \mathrm{g} / \mathrm{ml})$ & aMean conc. \pm SD $(\mu \mathrm{g} / \mathrm{ml})$ & \% Deviation \\
\hline 25 & 4.135 & 4.134 & 4.057 & $4.109 \pm 0.045$ & +10.90 \\
\hline 30 & 3.755 & 3.687 & 3.672 & $3.705 \pm 0.044(100 \%)$ & --- \\
\hline 35 & 3.516 & 3.515 & 3.495 & $3.509 \pm 0.012$ & -5.29 \\
\hline
\end{tabular}

amean \pm SD for 3 determinations

Table 6: Results of stability study

\begin{tabular}{lllll}
\hline Initial conc. $(\boldsymbol{\mu g} / \mathbf{m l})$ & Run 1 $(\boldsymbol{\mu g} / \mathbf{m l})$ & Run $\mathbf{2}(\boldsymbol{\mu g} / \mathbf{m l})$ & Run 3 $(\boldsymbol{\mu g} / \mathbf{m l})$ & aMean conc. $\mathbf{M D D}(\boldsymbol{\mu g} / \mathbf{m l})$ \\
\hline 3.705 & 3.694 & 3.596 & 3.436 & $3.575 \pm 0.130$ \\
\hline
\end{tabular}

amean \pm SD for 3 determinations

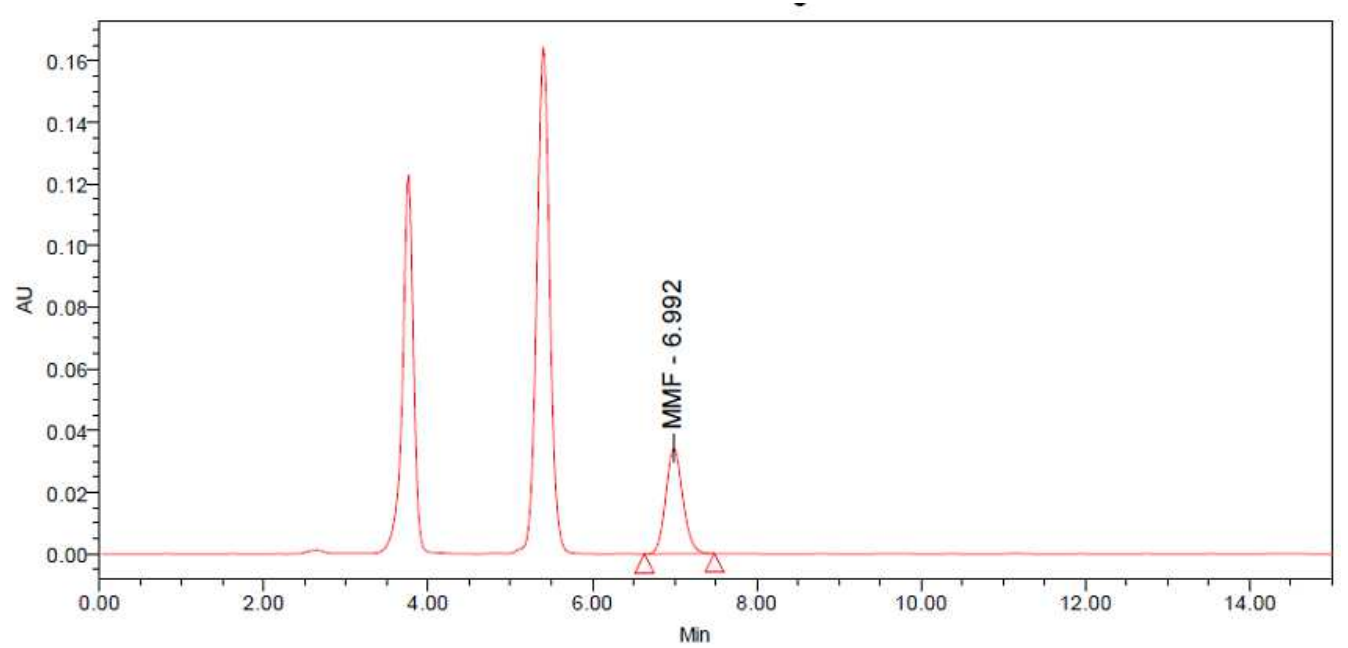

Fig. 5: Representative chromatogram of a test sample used for determination of drug content (Mycophenolate Mofetil) in a microemulsion formulation 


\section{DISCUSSION}

Analytical procedure explains the method by which analysis can be performed and describes the steps necessary for the analytical test. Validation of an analytical method establishes documented evidence and provides a high degree of assurance that the method will consistently produce the desired result meeting its predetermined specifications and quality characteristics [14]. The UV absorption spectrum of the representative sample $(10 \mu \mathrm{g} / \mathrm{ml})$ of MMF was scanned and showed three major peaks at $215 \mathrm{~nm}$, $250 \mathrm{~nm}$, and $304 \mathrm{~nm}$. In spite of maximum absorbance as compared to the other two peaks, $215 \mathrm{~nm}$ was not selected for our study, assuming it might have interaction with micro emulsion compositions. Between $250 \mathrm{~nm}$ and $304 \mathrm{~nm}, 250 \mathrm{~nm}$ was chosen as $\lambda_{\max }$ due to its higher absorbance value. The constructed calibration curve resulted in a coefficient of correlation value 0.9996, which indicates a linear relationship between the concentrations of analyte and areas of the corresponding peaks. The results of accuracy and precision were found to be within the limits of ICH Q2 (R1) guidelines [15].

The results of robustness studies showed that a minor change of method conditions such as the compositions of the mobile phase, flow rate and temperature, is robust within the acceptable limits. The $\%$ deviation between actual and observed concentration was calculated. The results show that \% deviation for change in compositions of the mobile phase, flow rate and temperature was within a range of-5.51 to $10.99 \%,-3.70$ to $8.80 \%$ and -5.29 to $10.90 \%$, respectively. The method seems sensitive to change in temperature $\left( \pm 5^{\circ} \mathrm{C}\right)$ and methanol composition $( \pm 2 \%)$ as the results were at the boundary limit of $10 \%$ deviation. However, the changes below $\pm 5{ }^{\circ} \mathrm{C}$ and $\pm 2 \%$ methanol should not affect the method.

The sample was found quite stable; maximum degradation was found at 3.51\%. The results (table 6) show that the developed HPLC method for estimation of MMF is quite stable up to $24 \mathrm{~h}$. The developed HPLC method was successfully applied to estimate the content of MMF present in the developed micro emulsion formulation.

\section{CONCLUSION}

An HPLC method for the estimation of MMF was developed and validated as per ICH Q2 (R1) guidelines. A simple mobile phase consisting of only water and methanol at 75 and 25 ratios (v/v) was used. The developed method was very much sensitive, with LOD and LOQ values of $3.660 \mathrm{ng} / \mathrm{ml}$ and $11.091 \mathrm{ng} / \mathrm{ml}$, respectively. The method was linear in the range of 0.1 to 10 $\mu \mathrm{g} / \mathrm{ml}$. Accuracy, precision, stability and robustness parameters were within limits. The developed method was successfully utilized to estimate drug content of a developed micro emulsion formulation.

\section{ACKNOWLEDGMENT}

Authors acknowledge contributions of gift samples from Conchord Biotech, Ahmedabad, India; Gattefosse India Private Limited, Mumbai, India and Croda Inc, USA.

\section{FUNDING}

\section{AUTHORS CONTRIBUTIONS}

All the authors have contributed equally in this study. All the authors have read and approved the final manuscript.

\section{CONFLICTS OF INTERESTS}

Authors declare that there is no conflict of interest regarding the publication of this article.

\section{REFERENCES}

1. Scheubel E, Adamy L, Cardot JM. Mycophenolate mofetil: use of a simple dissolution technique to assess generic formulation differences. Dissolution Technol 2012;19:52-8.

2. Sarwal MM, Yorgin PD, Alexander S, Millan MT, Belson A, Belanger $\mathrm{N}$, et al. Promising early outcomes with a novel, complete steroid avoidance immunosuppression protocol in pediatric renal transplantation1. Transplantation 2001;72:13-21.

3. Johnson DW, Nicol DL, Purdie DM, Preston JM, Brown AM, Carmel $\mathrm{M}$, et al. Is mycophenolate mofetil less safe than azathioprine in elderly renal transplant recipients? Transplantation 2002;73:1158-63.

4. Allison AC, Eugui EM. Immunosuppressive and other effects of mycophenolic acid and an ester prodrug, mycophenolate mofetil. Immunol Rev 1993;136:5-28.

5. Mele TS, Halloran PF. The use of mycophenolate mofetil in transplant recipients. Immunopharmacology 2000;47:215-45.

6. Nousari HC, Sragovich A, Kimyai Asadi A, Orlinsky D, Anhalt GJ. Mycophenolate mofetil in autoimmune and inflammatory skin disorders. J Am Acad Dermatol 1999;40:265-8.

7. Chaudhry V, Cornblath DR, Griffin JW, O'Brien R, Drachman DB. Mycophenolate mofetil: a safe and promising immunosuppressant in neuromuscular diseases. Neurology 2001;56:94 LP-96.

8. Guideline ICHHT. Validation of analytical procedures: text and methodology Q2 (R1). In: International Conference on Harmonization, Geneva, Switzerland; 2005. p. 11-2.

9. Reddy T, Ramu G, Kumar MS, Rambabu C. Validated RP-HPLC method for the determination of mycophenolate mofetil in tablet dosage forms. Asian J Chem 2013;25:4788.

10. Rao AL, Srinivas PV, Rao J. A new validated RP-HPLC method for the estimation of mycophenolate mofetil in pure and tablet dosage form. Asian J Pharm Res Heal Care 2010;2:266-9.

11. Tsina I, Kaloostian M, Lee R, Tarnowski T, Wong B. Highperformance liquid chromatographic method for the determination of mycophenolate mofetil in human plasma. J Chromatogr B: Biomed Sci Appl 1996;681:347-53.

12. Sharma S, Goyal S, Chauhan K. A review on analytical method development and validation. Int J Appl Pharm 2018;10:8-15.

13. Nagavi BJ, Gurupadayya BA. Simultaneous estimation of clopidogrel and atorvastatin in human plasma using bioanalytical RP-ultra fast liquid chromatographic method. Int J Curr Pharm Res 2015;7:30-5.

14. Kunithala VK, Chinthakindi KK, Vemula SK, Garepally PR, Bontha VK. A new rapid and simple analytical method development and validation of estimation of the mycophenolate in dosage form by UPLC technique. Asian J Pharm Clin Res 2012;5:233-7.

15. Sharma T, Mishra N, Moitra SS, Sankar DG. A validated RPHPLC method for estimation of tenofovir disoproxil fumarate in bulk and pharmaceutical formulation. Asian J Pharm Clin Res 2012;5:108-10. 